\title{
A INDETERMINAÇÃO EM ESAÚ E JACÓ PROBLEMÁTICA DE UMA LITERATURA EXTERIOR
}

por Tiago Guilherme Pinheiro ${ }^{1}$

\begin{abstract}
RESUMO: Este artigo pretende esboçar uma análise da construção de uma literatura exterior dentro da obra de Joaquim Maria Machado de Assis e de como essa estratégia textual se problematiza a partir das novas relações que estabelece entre autor, narrador e leitor.
\end{abstract}

PALAVRaS-ChAVES: Machado de Assis, Esaú e Jacó, Literatura exterior, Neutralização.

ABSTRACT: This article tries to sketch an analysis of the construction of an external literature in the work of Joaquim Maria Machado de Assis and how this textual strategy put itself in doubt from the new relations settled between author, narrator and reader.

KEYWORDS: Machado de Assis, Esau and Jacob, External literature, Neutralization.

\section{EXTERIORIDADE DO TEXTO MACHADIANO}

A partir da história da fortuna crítica produzida sobre a obra de Machado de Assis é possível analisar um problema que se estabelece na literatura desde o século XIX: o problema da indeterminação do significado último do texto. Livros como Memórias Póstumas de Brás Cubas e Dom Casmurro deslocam os dispositivos utilizados para garantir o valor de verdade de um texto - o autor, a origem, o efeito mimético, o valor moral e institucional - para recolocá-los e resignificá-los dentro de um espaço novo, "neutro" (BLANCHOT, 1987). A tentativa de preencher esse espaço está no cerne da grande variedade de significações - muitas vezes antagônicas - envolvendo os personagens-narradores, sobre a (in)legitimidade de suas ações frente a seu próprio criador. ${ }^{2}$ Sem dúvida, a ruptura entre o autor empírico e o autor ficcional é fundamental para a acepção de "texto literário" que se tornou corrente desde esse período, pois é a partir dessa estratégia (dentre outras) que a literatura ganha um campo que possui alto grau de autonomia, regido por suas próprias leis e valores (BOURDIEU, 1998). No caso dos romances citados, essa ruptura ocorre de forma particularmente radical: não podemos, com garantias, oferecer uma linha contínua entre os valores de Machado de Assis e Bentinho ou Brás Cubas, e inclusive somos impelidos a ver nessa relação algo de profundamente problemático ${ }^{3}$. Dessa

\footnotetext{
${ }^{1}$ Mestrando do Departamento de Teoria Literária e Literatura Comparada da Universidade de São Paulo.

${ }^{2}$ Comparar, por exemplo, as leituras de Dom Casmurro feitas por Roberto Schwarz em Duas Meninas (2000) e Alfredo Bosi, em Machado de Assis: o enigma do olhar (2007).

${ }^{3}$ Isso se deve, entre outros motivos, pelos próprios modelos tomados por ambos os livros: os romances de tese, os contos filosóficos e as narrativas morais. É impressionante que para Machado de Assis romper com a dependência das instituições que pautavam a literatura e que ainda exerciam poder sobre ela durante o século XIX brasileiro, ele tenha regressado as formas submissas (e objetivas) típicas do século anterior.
} 
forma, a literatura começa a atuar distintamente de instituições morais, religiosas ou mesmo jurídicas - nesse caso, ela passa a ser um espaço no qual a Lei se reconhece (ao mesmo tempo em que se estabelece) como ausente. Isso ocorre porque toda a relação estabelecida entre o texto e a sua origem (o escritor) pode ser anulada como "ficcional", como "liberdade poética". Essa estratégia, que passa a se tornar onipresente no século XX, faz da literatura um espaço expressivo privilegiado, já que a partir daí a literatura pode exercer um papel crítico em relação às outras instituições sociais, das quais antes dependia. Essa relação fica visível no ensaio de Machado de Assis (1994 [1893]) intitulado "Notícia da atual literatura brasileira. Instinto de nacionalidade":

Não há dúvida que uma literatura, sobretudo uma literatura nascente, deve principalmente alimentar-se dos assuntos que lhe oferece a sua região; mas não estabeleçamos doutrinas tão absolutas que a empobreçam. O que se deve exigir do escritor antes de tudo, é certo sentimento íntimo, que o torne homem do seu tempo e do seu país, ainda quando trate de assuntos remotos no tempo e no espaço. Um notável crítico da França, analisando há tempos um escritor escocês, Masson, com muito acerto dizia que do mesmo modo que se podia ser bretão sem falar sempre do tojo, assim Masson era bem escocês, sem dizer palavra do cardo, e explicava o dito acrescentando que havia nele um scotticismo interior, diverso e melhor do que se fora apenas superficial. (p.804)

A preocupação de Machado de Assis está relacionada a uma questão políticoinstitucional, mas ele defende uma aproximação diferencial do assunto, a partir da literatura, que tem o direito de escolher o assunto que lhe aprouver. A dupla preocupação do escritor se dá por um lado, pela abordagem de assuntos políticos, e, por outro, pela definição de um espaço sem limites, evitando toda a determinação (nesse trecho, principalmente a de ordem temática) que possa responder a esse $e$ a outros assuntos, quaisquer assuntos, pelo próprio afastamento deles. Talvez o abandono, por parte de Machado de Assis, do trabalho propriamente crítico, em favor de uma prática somente "literária", esteja baseado no temor de qualquer possível normatividade advinda de uma atividade sobre a outra (note o número de ressalvas feitas a cada afirmação por todo o ensaio, matizando cada afirmação, deixando sempre as possibilidades em aberto). Dessa forma, Machado de Assis se aproxima do conceito de intelectual tal como proposto por Pierre Bourdieu (1998):

L'intellectuel se constitue comme tel en intervenant dans le champ politique $a u$ nom d'autonomie et des valeurs spécifiques d'un champ de production culturelle parvenu à un haut dégré d'indépendance à l'égard des pouvoirs (et non, comme l'homme politique à fort capital culturel, sur la base d'une autorité proprement politique, acquise au prix d'un renoncement à la carrière et aux valeurs intellectuelles). (p. 216-217. O grifo é do autor)

Como afirma Natali (2007), esse lugar distinto foi um elemento estratégico importante na literatura dissidente:

Não seria possível inclusive contar a história do surgimento da noção moderna de ficção como uma tentativa de escapar das restrições da lei, instituindo uma nova relação entre o sujeito (o autor), o discurso e a lei? O texto ficcional é, afinal, aquele em que o enunciador não é responsável perante a lei, ou seja, onde tudo poderia ser dito, sem limites. 
Não que essa crítica se enuncie pela oposição de um sistema de valores a outro, pela elevação de Capitu em detrimento do grande patriarca Dom Casmurro, mas pela própria indeterminação de qualquer certeza advinda de um espaço que nos é exterior (FOUCAULT, 1986 numa transposição do conceito já apresentado de Blanchot), já que a literatura não está mais (totalmente) determinada por regimes de verdade (sejam eles os metafísicos, sociais ou mesmo econômicos). Ao se instalar fora, ou melhor, ao lado, em "paródia" (AGAMBEN, 2008) , a $^{4}$ literatura problematiza os conteúdos sociais dados, revelando sua arbitrariedade, o não-fim de uma objetividade que se quer última. Por isso, qualquer interpretação desses dois romances que encontre em qualquer ponto algum valor "positivo" estará sempre em tensão entre a submissão de seu conteúdo e a exterioridade do texto literário, que resistirá continuamente a qualquer fechamento. A literatura não oferece garantias.

Hansen (2008), em sua análise de Dom Casmurro, opondo-se ao que chama de "leituras intencionalistas", explicita bem esse movimento, que se revela nas estratégias adotadas no próprio texto literário:

Esse modo de neutralizar as significações familiares e previsíveis, que é observável em seu compromisso exclusivamente artístico com a forma, talvez pretendesse a autonomia de uma liberdade estética que recusava a instrumentalização da arte, inclusive a ideologia naturalista da literatura como semelhança documental e refletora da realidade empírica, que, com ele, se torna indeterminada. A ficção escrita como questionamento da possibilidade da existência da ficção é um dos temas privilegiados da sua arte inventada como uma singular teoria da enunciação. (p.154)

Assim, para Hansen, o potencial elucidativo da literatura estaria no seu próprio local de enunciação, que, devido à própria impossibilidade de objetivação garantida pela exterioridade que constitui (e é constituída por) esse objeto singular, negaria um uso instrumental da linguagem, sua adequação a um real pré-determinado.

Entretanto, segundo o que esse artigo pretende sugerir a partir de uma leitura do romance Esaú e Jacó, o surgimento desse espaço autônomo externo resulta em problemas adicionais para o poder crítico da instituição literária.

\section{O NARRADOR ADIADO EM ESAÚ E JACÓ}

Se em Memórias Póstumas ou em Dom Casmurro, encontramos uma tentativa de distinção entre autor empírico e autor ficcional, em Esaú e Jacó essa problematização não se dá por uma pura ruptura, mas através de um adiamento (DERRIDA, 1973) da origem do texto,

\footnotetext{
${ }^{4}$ Giorgio Agamben retoma o sentido original da palavra "paródia" (do grego para tem oden, "contra" ou "ao lado do canto"). Assim, paródia seria a imitação ou a repetição (marcada, muitas vezes, por uma possível infantilidade ou ignorância) de algo que é inalcançável, ininteligível, uma renuncia pela representação direta do objeto. Dessa forma, poderíamos apontar em Dom Casmurro uma estrutura linguística (a paródia aqui deixa de ser mera figura de linguagem) que busca colocar em paralelo (paralelos em relação ao próprio romance) os "motivos" de Capitu e Bentinho, devido à própria indeterminação, não só da literatura, mas da própria "realidade" com a qual esses motivos se configuram. Cf. Agamben, Giorgio."Paródia”. In: Profanações. São Paulo: Boitempo, 2008.
} 
multiplicando e entretecendo as diversas "fontes" do texto. Segundo a "Advertência" que abre o livro, tal narrativa fora encontrada junto aos diários do Conselheiro Aires.

Quando o Conselheiro Aires faleceu, acharam-se-lhe na secretária sete cadernos manuscritos, rijamente encapados em papelão. Cada um dos primeiros seis tinha o seu número de ordem, por algarismos romanos, I, II, III, IV, V, VI, escritos tinta encarnada. O sétimo trazia este título: Último.

$[\ldots]$

A hipótese de que o desejo do finado fosse imprimir este caderno em seguida aos outros, não é natural, salvo se queria obrigar à leitura dos seis, em que tratava de si, antes que lhe conhecessem esta outra história, escrita com um pensamento interior e único, através das páginas diversas. Nesse caso, era a vaidade do homem que falava, mas a vaidade não fazia parte dos seus defeitos. Quando fizesse, valia a pena satisfazê-la? Ele não representou papel eminente neste mundo; percorreu a carreira diplomática, e aposentou-se. Nos lazeres do ofício, escreveu o Memorial, que, aparado das páginas mortas ou escuras, apenas daria (e talvez dê) para matar o tempo da barca de Petrópolis. Tal foi a razão de se publicar somente a narrativa. Quanto ao título, foram lembrados vários, em que o assunto se pudesse resumir. Ab ovo, por exemplo, apesar do latim; venceu, porém, a idéia de lhe dar estes dois nomes que o próprio Aires citou uma vez:

\section{ESAÚ E JACÓ}

(MACHADO DE ASSIS, 2003, p. 9-10)

Já nessa primeira aparição do "organizador" da texto (que interfere diversas vezes durante a narrativa), põe-se em questão uma apropriação silenciosa da história deixada por Aires, começando pela modificação do título, além da própria transgressão dos planos de publicação do morto, julgando que lançar os diários antes do romance seria apenas um desejo imposto pela vaidade.

Esse processo estende-se por todo o romance, no qual Aires figura antes como personagem do que como narrador. É verdade que continuamente se estabelece a lembrança de que Aires é a fonte primaria do texto; contudo, sua confiabilidade é insistentemente (e até mesmo de forma suspeita) reiterada pelo narrador, invertendo a técnica romântica na qual o testemunho de um terceiro dá veracidade ao narrador (aqui é o narrador que dá veracidade ao escrito, inclusive corrigindo e adivinhando o interesse oculto nas palavras escritas no Memorial). $\mathrm{O}$ capítulo XII, "Esse Aires", é um exemplo entre vários de como se dá essa legitimação. O narrador enumera as diversas qualidades de Aires, inclusive sua estranha espécie de "sinceridade" com relação aos assuntos da sociedade - uma sinceridade privada, que se dá apenas em seu diário, mas que falha publicamente, já que ele tinha "tédio à controvérsia", nunca se opondo ao seu interlocutor.

Era cordato, repito, embora esta palavra não exprima exatamente o que quero dizer. Tinha o coração disposto a aceitar tudo, não por inclinação à harmonia, senão por tédio à controvérsia

[...]

Não cuides que não era sincero, era-o. Quando não acertava de ter a mesma opinião, e valia a pena escrever a sua, escrevia-a. Usava também guardar por 
escrito as descobertas, observações, reflexões, críticas e anedotas, tendo para isso uma série de cadernos, a que dava o nome de Memorial (MACHADO DE ASSIS, 2003, p.38)

Novamente, põe-se em questão a "sinceridade" de Aires, em contraste com a sua atuação como autor do diário (que aqui é inacessível para nós). A possibilidade desse questionamento expande ainda mais as consequências dos processos expostos nos romances anteriores: a distinção entre autor e obra não aparece apenas como uma estratégia literária, mas como descentramento aplicável a qualquer texto - a inverdade é incorrigível (mesmo quando é escrita de si para si, como no caso do diário), mesmo quando há a interferência de um terceiro, supostamente afastado e desinteressado. Na verdade, esse processo sempre ocorre devido a esse terceiro (e um quarto, um quinto, ad infinitum), que está sempre presente, e que nunca é desinteressado. A externalidade, a indefinição do conteúdo da narrativa, é duplicada e mesmo triplicada. Assim, fica posto em questão o papel da assinatura "Machado de Assis" colocada na capa do romance. Esse dispositivo - a assinatura - já não mais demarca nem posse (como durante as obras de arte durante Idade Média - vide FOUCAULT, 1992), nem origem, mas um uso, ou melhor, um índice que, em paralaxe, camufla o uso de um texto. Dessa forma, não cabe perguntar qual nome determina o texto - Machado de Assis, Aires, o narrador anônimo, o leitor ou mesmo uma pura mímesis sem nome, identificada como "verdade" (seja como ideologia ou como desvelamento da ideologia) -, mas como cada um desses "autores" permeia o romance, inscrevendo-se pelo uso que faz do texto. As assinaturas passam a formar o próprio texto, que se transforma ele próprio numa série cumulativa: um palimpsesto cuja inscrição mais recente (sempre localizada no presente imediato) está sempre sob ameaça do apagamento, devido à "incerteza" provocada por sua indeterminação. Ao expor todos esses atores que rascunham (sobre) a história, Machado de Assis (e eu mesmo - também autor deste texto e do outro) deixa claro que o sentido de um texto se determina por uma disputa simbólica na qual o que está em jogo não é a literatura (ela em si jamais constituí um valor). Aqui as relações de interesse fazem parte do próprio processo de formação da escrita literária.

Diferente de Memórias Póstumas ou Dom Casmurro, no qual esses elementos já aparecem desenhados, Esaú e Jacó inverte a perspectiva dos efeitos da externalidade do romance, na medida em que não estão garantidos também os efeitos pretendidos por seu "autor empírico". Esse conflito aparece com todas as letras no episódio do discurso de Paulo e suas interpretações como "monarquista liberal" feitas pelo seu próprio pai e irmão:

Pelas férias é que Paulo soube da interpretação que o pai dera à Regente daquele trecho do discurso. Protestou contra ela, em casa; quis fazê-lo também em público, mas Natividade interveio a tempo. Aires pôs água na fervura, dizendo ao futuro bacharel:

— Não vale a pena, moço; o que importa é que cada um tenha as suas idéias e se bata por elas, até que elas vençam. Agora que outros as interpretem mal é coisa que não deve afligir o autor.

- Afligir, sim, senhor; pode parecer que é assim mesmo... Vou escrever um artigo a propósito de qualquer coisa, e não deixarei dúvidas...

- Para quê? inquiriu Aires.

- Não quero que suponham...

— Mas quem duvida dos seus sentimentos?

- Podem duvidar. 
- Ora, qual! Em todo caso, vá primeiro almoçar comigo um dia destes... Olhe, vá domingo, e seu irmão Pedro também. Seremos três à mesa, um almoço de rapazes. Beberemos certo vinho que me deu o ministro da Alemanha... (MACHADO DE ASSIS, 2003, p. 93-94)

Como é comum nas obras de Machado de Assis, toda a discussão se dispersa durante as refeições ${ }^{5}$. Nesse trecho (e nesse romance, em geral) talvez se possa entrever uma reflexão sobre os limites e riscos da técnica da exterioridade, de uma literatura sem suportes se não ela mesma. Isso não quer dizer que tais técnicas fossem "falhas", mas sim que essas permitiam uma abertura que mesmo o próprio autor estivesse à parte, ou melhor, que ele mesmo não a considerasse indesejável. Pior: tal processo dispersaria as funções críticas da própria literatura, que passaria de neutra a "neutralizada" (DERRIDA, 1991): um espaço no qual tudo pode ser dito, mas que pode ser rapidamente dispensado como ficção, subjetividade ou indeterminação (justamente como acontece com o discurso de Paulo, que, de repente, se torna absolutamente conservador). Não é assim que devemos entender outra parte crucial do romance, que, no entanto, apresenta-se apenas como um entreato:

Enquanto os meses passam, fazer de conta que estás no teatro, entre um ato e outro, conversando. Lá dentro preparam a cena, e os artistas mudam de roupa. Não vás lá; deixa que a dama, no camarim, ria com os seus amigos o que chorou cá fora com os espectadores. Quanto ao jardim que se está fazendo, não te exponhas a vê-lo pelas costas; é pura lona velha sem pintura, porque só a parte do espectador é que tem verdes e flores. Deixa-te estar cá fora no camarote desta senhora. Examina-lhe os olhos; têm ainda as lágrimas que lhe arrancou a dama da peça. Fala-lhe da peça e dos artistas. Que é obscura. Que não sabem os papéis. Ou então que é tudo sublime. Depois percorre os camarotes com o binóculo, distribui justiça, chama belas às belas e feias às feias, e não te esqueças de contar anedotas que desfeiem as belas, e virtudes que componham as feias. As virtudes devem ser grandes e as anedotas engraçadas. Também as há banais, mas a mesma banalidade na boca de um bom narrador faz-se rara e preciosa. E verás como as lágrimas secam inteiramente, e a realidade substitui a ficção. Falo por imagem; sabes que tudo aqui é verdade pura e sem choro. (MACHADO DE ASSIS, 2003, p. 97)

Esse trecho é mais que uma quebra da chamada "ilusão ficcional": é a própria confissão da banalidade do texto, de como ele está envolvido por uma esfera de entretenimento barato e inofensivo. A realidade que substitui as lágrimas não é mais que um mundo mesquinho, esse sim a "verdade pura e sem choro" (pelo menos, dos leitores do livro). A negatividade da literatura provocada pelo seu lugar exterior à realidade dada - pode muito bem dar lugar a um refortalecimento desse "real", ao ser recalcada como "pura lona velha sem pintura". E, por isso mesmo, esconde tão bem os jogos de interesses que ocorrem em sua frente (e não somente atrás dos palcos).

É difícil precisar quais foram as reações provocadas em Machado de Assis pelos modos como os seus romances foram lidos em sua época; porém, a passividade de seus leitores (com

\footnotetext{
${ }^{5}$ No final do mesmo capítulo: "A política veio morrendo. Na verdade, Paulo ainda se declarou capaz de derrubar a monarquia com dez homens, e Pedro de extirpar o gérmen republicano com um decreto. Mas o ex-ministro, sem mais decreto que uma caçarola, nem mais homens que o seu cozinheiro, envolveu os dois regimes no mesmo salmão delicioso" (p. 96). Aparentemente, Aires foi quem levou essa técnica ao seu mais alto estágio.
} 
relação aos seus narradores que, por muito tempo, nunca foram postos em questionamento ${ }^{6}$ ) talvez o tenha inspirado a criar esse cenário de personagens pálidos descritos em Esaú e Jacó.

Com sua narrativa dispersiva (não sabemos quais dos enredos é realmente importante tudo aqui parece um pouco banal e tedioso, como o próprio narrador anônimo faz questão de lembrar constantemente), Machado de Assis coloca em cenário uma tipologia de intérpretes, não de "leitores ideais", mas de "leitores indesejados", de leitores fracos": os indecisos, absolutamente estáticos diante dos problemas (e não das soluções) colocados tantos na vida pública como na privada (Flora); os obstinados cegos, sem motivos, regidos pelas instituições que confirmam sua posição social, fazendo, aliás, que tudo concorde com essa posição, sejam os fatos, sejam os livros (Pedro e Paulo); e aquele que simplesmente se posiciona a favor de tudo, diplomaticamente, sem deixar mágoas nem mudanças, em si ou no mundo (Aires). Não é à toa que esse seja o "autor" original do texto, sua origem primeira ${ }^{8}$. Essa é a própria metáfora de como um romance cujo conteúdo seja "externo" pode se posicionar com relação aos seus leitores: em tudo lhes concordando, confirmando tudo, sem maiores problemas, estando sempre à margem da subjetivação (egocêntrica) do entendimento.

A construção desse romance é extremamente inteligente: a passividade de qualquer discurso passa pela própria passividade de seus leitores. Machado de Assis não somente aponta um esquema de leitura/escritura/apropriação, mas critica uma certa transformação da literatura em confirmação constante das estruturas sociais, já que suas leituras são feitas a partir dos interesses mesmo dessa sociedade. Paradoxalmente, a exterioridade da literatura, essa estratégia crítica tão fundamental durante os séculos XIX e XX, pode levá-la novamente a sua submissão aos interesses mais "institucionais" de uma sociedade.

Questão fundamental para a literatura contemporânea, Machado de Assis já teria visto em sua própria técnica um risco de saturação, de uma literatura demasiadamente ficcionalizada e de um mundo completamente subjetivizado.

Esaú e Jacó abre, dentro da obra de Machado de Assis, uma outra perspectiva sobre a estratégia discursiva empregada por dois romances anteriores, Memórias Póstumas de Brás Cubas e Dom Casmurro. Se nesses, o autor consegue criar uma série de rupturas que criam um espaço externo permitindo o escritor intervir como crítico dos valores estabelecidos pelas instituições que formam a sociedade, sem que passe a servir a qualquer uma delas; naquele, essa técnica passa a ser trabalhada tendo em vista seus próprios contornos e limites.

Lêem-se então os efeitos últimos dessa exterioridade do literário - a subjetivação e ficcionalização radicais dos conteúdos de um texto, a noção de autoria como rasura constante sobre o livro, a passividade com que a literatura passa a agir dentro de uma sociedade - em

\footnotetext{
${ }^{6}$ Seria coincidência que Esaú e Jacó sucedesse justamente Dom Casmurro? Cf. a fortuna crítica do período em Guimarães, Hélio de Seixas. Os leitores de Machado de Assis: o romance machadiano e o público de literatura no século 19. São Paulo: Nankin/ Edusp, 2004.

${ }^{7}$ Um esboço disso já aparece em Dom Casmurro, na interpretação realizada por Bentinho sobre Otelo de Shakespeare.

${ }^{8}$ A representação da estratégia do adiamento das certezas do texto literário estaria presente em Aires pela forma como ele parece deter algumas verdades, sem que ele jamais as revele, mesmo quando promete isso explicitamente. Um exemplo maior dentro do romance é a questão da inexplicabilidade de Flora: "Agora é tarde para lhe expor os fundamentos de minha impressão, depois lhe direi" (p.130). A verdade é que a explicação nunca vem.
} 
última análise, a problemática de uma leitura que não se localiza num espaço neutro, mas neutralizado. Nota-se então o dilema em que se encontra o próprio papel do escritor numa sociedade pontuada por um egocentrismo de classe, que ainda detém poderes sobre a instituição literária, por ser justamente a sua classe consumidora. $\mathbb{E}^{\mathrm{C}}$

Agradecimento: ao professor Hélio de Seixas Guimarães, cujo curso de Literatura Brasileira IV originou este texto.

\section{REFERÊNCIAS BIBLIOGRÁFICAS:}

AGAMBEN, Giorgio."Paródia”. In: Profanações. São Paulo: Boitempo, 2008.

ASSIS, Joaquim Maria Machado de. "Notícia da atual literatura brasileira. Instinto de nacionalidade". In: Obras Completas vol. III. Rio de Janeiro: Nova Aguilar, 1994. Dom Casmurro. In: Obras Completas vol. I. Rio de Janeiro: Nova Aguilar, 1994. Esaú e Jacó. São Paulo: Abril Cultural, 2003.

Memórias póstumas de Brás Cubas. In: Obras Completas vol. I. Rio de Janeiro: Nova Aguilar, 1994.

BLANCHOT, Maurice. Espaço literário. Rio de Janeiro: Rocco, 1987.

BOSI, Alfredo. Machado de Assis: o enigma do olhar. São Paulo: WMF Martins Fontes, 2007.

BOURDIEU, Pierre. Les règles de l'art: Genèse et structure du champ littéraire. Paris: Éditions de Seuil, 1998.

DERRIDA, Jacques. “Assinatura, Evento, Contexto". In: Margens da filosofia. Campinas: Papirus, 1991. . Gramatologia. São Paulo: Perspectiva, 1973.

FOUCAULT, Michel. La pensée du dehors. Paris: Fata morgana, 1986. O que é um autor?. S.1.: Passagens, 1992.

GUIMARÃES, Hélio de Seixas. Os leitores de Machado de Assis: o romance machadiano e o público de literatura no século 19. São Paulo: Nankin/ Edusp, 2004.

HANSEN, João Adolfo. "Dom Casmurro: simulacro e alegoria". In: Guidin, Márcia Lígia; Granja, Lúcia; Ricieri, Francine Weiss (Orgs.). Machado de Assis: Ensaios da crítica contemporânea. São Paulo: Unesp, 2008.

NATALI, Marcos Piason. "Antifetichismo e revelação: Notas em torno de 'Dos cuentos católicos' de Roberto Bolaño". Comunicação apresentada no XI Encontro Regional da ABRALIC, 2007.

SCHWARZ, Roberto. Um mestre na periferia do capitalismo. São Paulo: Editora 34, 2000. Duas meninas. São Paulo: Companhia das Letras, 1997. 